\title{
Strengthening Capacities of Ward Development Committees to Promote Health in Nigeria: A Case Study of Osun State
}

\author{
Helen U. Ekpo ${ }^{1 *}$, Nnodimele O. Atulomah ${ }^{2}$ \\ ${ }^{1}$ Department of Public Health, Texila American University, Guyana \\ ${ }^{2}$ Department of Public Health, Babcock University, Ogun State
}

\begin{abstract}
Unsatisfactory health indices characterize Osun State Nigeria Primary Health Care facilities and poor operational conditions. Residents patronize private health facilities with attendant payment of huge out-of-pocket medical bills. Implementation of the Basic Health Care Provision Fund (BHCPF), a mechanism to increase access to quality health care for all its citizens initiated by the state government, commenced in 2018. The study sought to determine the extent to which capacity building/training of Ward development committees (WDC) in BHCPF supported PHCs has contributed to the provision of quality health services in the BHCPF supported facilities. The study was qualitative in design and used three focus group discussions held in three BHCPF implementing LGAs with thirtyfive (27males, 8 females) consenting trained WDC members. Prior to the BHCPF training, the majority of the WDCs were not actively involved in the management of their PHCs, as political appointees and were unclear about their roles and responsibilities to the health facilities in their wards. After the training, most of the trained WDCs engaged with their PHC staff to debrief, review the quality improvement plans for their health facilities, identified immediate needs to address, approached influential people in the community, and mobilized local resources to address identified gaps. Electricity and water supply were restored in most of the facilities, hospital beds and basic equipment for were procured for PHCs, building, and equipping of the laboratory were completed. Building the capacity of the WDC on their roles and responsibilities strengthened them to contribute to the provision of quality health services in their communities.
\end{abstract}

Keywords: Access, capacity building, quality improvement, Universal Health Coverage, Ward development committees.

\section{Introduction}

Nigeria is considered to have one of the worst health indices in the world and contributes to 10 percent of the global maternal deaths. In Nigeria, the under-five mortality rate (U5MR) and the maternal mortality rate is reducing but not as expected considering all the various initiatives that have been implemented over the passing decades. With a U5MR of 132 per 1000 live births and maternal mortality rate of 512 deaths per 100,000 live births $[1,2,3]$, translated to mean that one Nigerian woman dies in childbirth every 10 minutes, and one Nigerian child under-
5 years of age die every minute. The Multiple Indicator Cluster Survey (MICS) conducted by the national bureau of statistics and UNICEF in 2016 to 2017 showed that the maternal mortality rate in Osun was 169/100,000 live birth and U5MR was 101/1000LB [4].

The commitment of Nigeria to the improvement of maternal and child health indices as well as Universal Health Coverage was symbolised by the enactment of the National Health Act of 2014, section 11, which mandated the establishment of a Basic Health Care Provision Fund (BHCPF) [5]. This large-scale health sector reform effort sought to expand the 
fiscal space by deploying financial resources to the frontlines for primary health care services. The BHCPF is designed to be a sustainable model for ensuring equity and financial risk protection for vulnerable populations by guaranteeing access to a basic minimum package of health services [6].

Under the BHCPF, pregnant women are to receive antenatal care, child delivery care (Including caesarian section), and immunization free of charge. Children of under 5 years of age are to receive immunization, treatment for malaria, measles, pneumonia, and dysentery free of charge. The funding of the BHCPF is financed by an annual grant from the Federal Government of Nigeria (FGN), stipulating a budget of not less than one percent of the Consolidated Revenue Fund (CRF), grants from international donor agencies, and states government counterpart funding. Expectations of strategic implementation of the BHCPF would result in improved national and states health indices and firmly place Nigeria on the path to achieving universal health coverage [6]. Despite the introduction of the scheme, many healthcare systems in various states have not been obliged to adopt the scheme [7].

The Osun state government in 2017 met the requirements for accessing National BHCPF financing and in 2018 took a bold step to commence the implementation of BHCPF in one focal PHC per ward (a total of 332 PHCs in 30 LGAs), beginning with the renovation and providing essential equipment of the focal PHCs, strengthening capacities (training, mentoring, coaching and supportive supervision) of health workers and ward development committee (WDC) members for efficient utilization of BHCPF to provide basic minimum health care services package to the people of Osun state as a means of achieving the universal health care coverage $[8,9]$. The Ward development committee exists at the community level as part of the implementation of the Ward Health System (WHS), to enable mobilisation and governance of community resources. In line with national policy, the WDCs are expected to be involved in joint management of the PHC facilities and service delivery, together with health workers [10, 11]. This study was undertaken in Osun State to document the extent to which training of WDCs, in BHCPF has contributed to the provision of quality services in the focal PHCs and increased access to healthcare for residents.

\section{Materials and Methods}

\section{Study Design, Subjects, and Settings}

This is a qualitative study to explore the place of capacity building and strengthening of WDCs in ensuring that quality healthcare services are provided at BHCPF supported facilities in Osun state. Osun State is in the southwestern geopolitical region of Nigeria and consists of 30 local government areas (LGAs), with a total landmass of about 9,251 square kilometers, and is home to an estimated population of 5.1 million people in 2019 (Osun SBS, 2019). Three (3) focus group discussions (FGD) were conducted with WDCs who were trained on the BHCPF program and were involved in the management of the PHC in their wards. The first FGD was conducted on the $18^{\text {th }}$ of April 2019, with 10 trained WDCs from Osogbo LGA in Osun Central senatorial district, the $2^{\text {nd }}$ FGD held on the $24^{\text {th }}$ of May 2019 with 10 BHCPF trained selected WDCs from Oriade LGA in Osun East senatorial district, and the $3^{\text {rd }}$ FGD occurred on the $19^{\text {th }}$ of June 2019 with 15 trained WDCs from Ejigbo LGA of the Osun West senatorial district. A total of 35 (27males, 8 females) trained WDC members consented and participated in the focus group discussions, which were held 2 weeks after their BHCPF training. The study protocol was submitted to the Ethical committee of the Osun State Ministry of Health, and approval for the study was obtained to conduct the study.

Each focus group discussion session was one hour with the lead investigator for the study as the moderator for the 3 FGDs assisted by 2 officers of the Osun State Ministry of health as note-takers. The FGD guide and checklist was 
predetermined, open-ended questions about the BHCPF training and elicited feedback on the accomplishment of the WDCs immediately after the training. The focus group discussions were structured to cover specific topics, including: (1) role of the WDCs prior to the training, (2) the training experience (3) Engagement of WDCs with community-level stakeholders in health. The principal investigator guided the discussion from one planned topic to another during the focus group discussions. Transcripts of the focus groups were independently coded based on key themes and emergent categories related to the roles of the WDC prior to the training, the training experience, and engagement with community stakeholders in health. The qualitative data was thematically analyzed to achieve research objectives by identifying common themes within each FGD response from the LGAs and identifying and recording commonalities and differences.

\section{Results}

\section{Focus Group Discussion Participants}

The participants were predominantly men, $83 \%$, while women constituted $17 \%$ of WDCs that participated in the focus group discussions from the selected 3 LGAs from each of senatorial districts in Osun State. The focus group discussion guide consisted of open-ended questions used to elicit a variety of participant's responses regarding the participants' perspectives regarding their experiences, and the qualitative analysis uncovered an assortment of main themes. These are outlined below, including memorable quotes from participants.

\section{Set up of WDC}

The focus group discussion revealed that the majority of the WDCs in Osun state were set up by the state primary health care development agency. However, the guidelines for constituting members of the WDCs have not been strictly followed, as there are very few women represented in most committees, and local government chairmen have used their offices to nominate political affiliates from the wards as part of members.

"In most wards prior to strict guidelines from the PHCDB, on the composition and structure of the committees, members were selected from each village /clan that makes up the community, these are few men and women who are committed and have interest in the wellbeing of their people. They are mostly elderly people, and not all the villages are represented in the WDC as sometimes people who build houses around the health facilities were selected to be part of the WDC, and as such, some communities/villages are not represented in the $W D C " \mathrm{OM}$.

\section{Focus Group Discussion participants}

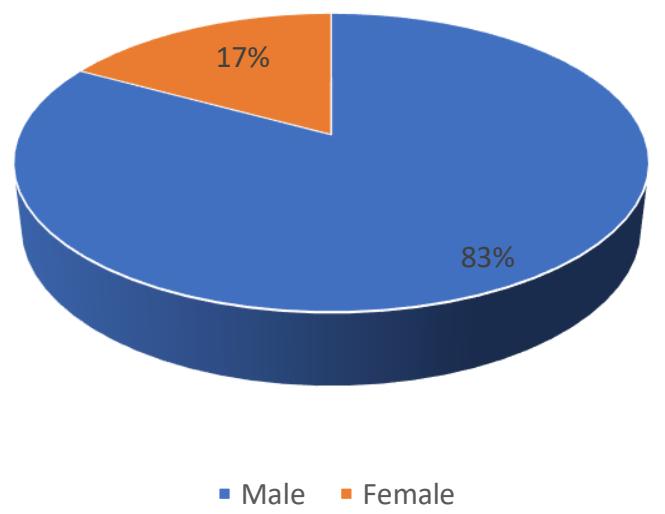

Figure 1. Percentage of Focus Group Discussion Participants by Sex 


\section{Constitution and Composition of Ward Development Committees in Osun State}

Most of the WDCs in Osun had few women representation, and in some, there are no women represented in the committees, hence considered an all-men affair. It was reported that this lack of women representation emerged from the observed lack of active participation of women in the local politics, only very few are women who are strong politically, and women in their wards are part of the committees.

"eeeh in my LGA-Oriade, there are very few women among us, it is not as if, they are not selected to join the fact is that they like money too much and whatsoever will take their time and not give money is not counted as important to them. So, when they are nominated to be part of the WDC, you find out that they won't come for meetings regularly complain ti poju. They might be part of the WDC but not active at all."

\section{Role of WDC in Health Management}

When participants were asked if they were familiar or aware of their roles and responsibilities as WDC members as it relates to the management of the PHCs prior to the BHCPF training, the majority stated that they were not informed clearly of their roles, but often the officer in charge of their facilities do approach them for specific assistance to address immediate needs at the PHCs. For instance, a complaint about a leaking roof, lack of or inadequate drugs supply, or lack of basic functional equipment and securing the PHCs. The WDCs reported addressing some of the issues by approaching community members for help or the LGA chairmen to support.

"In my ward, we never used to have meetings with the facilities staff just as my colleagues here said if there is any problem, the OIC will inform us, and we try to solve the problem. We did not take the issue of mobilizing the community to access services in the PHC as a priority as our people prefer the quacks and traditional medicine healers. But now it is very different oo" ANM.
"In my own ward, the WDCs were not aware of going to inform people about the services in the health facilities, in fact, I personally did not know that was part of my job, most of us see the position as part of our political benefits and were only concerned about what was in it for us, so we did not do much except for once in a while walking into the facilities to greet the staff and play with them then we also use to discuss current issues so did not contribute much to solving problems in the facilities" TM.

\section{Capacity Building on BHCPF for WDCs}

Most of the participants had diverse expectations of the training. According to the participants, the workshop enhanced their understanding regarding their roles and responsibilities as WDCs managing health facilities in their wards. Some of the misconceptions about the training by the WDCs, included thinking that they might be expected to provide some clinical services at the PHC, some felt they would gather skills to enable them to supervise the health workers at the facilities and hold them accountable, while others felt the training was part of dividend of democracy as an incentive for being loyal party members and the new health care program will be more accessible or affordable for the party members in the communities. However, their expectation and misconceptions concerning the training and BHCPF program in the wards changed from the 1st day of participating in the workshop. As explained by WDC from Isale osolo ward in Ejigbo LGA.

"For me, I thought since the training was on health issues and you know they trained us with our OICs, so I thought the training will be on how to provide treatment for minor injuries and how to give injections in fact, I met with one of the facilitators to ask when will they start teaching that aspect. it was then the facilitator had to explain to me and the entire class the purpose of the workshop and why they had to be trained with the OICs so that we as WDCs can have an understanding of the task for the health 
care workers in ensuring the success of the $B H C P F$ program in the ward and the support needed from the WDCs to ensure all go as planned" YM.

Explaining further, a few of the WDC representatives said when they came on board, a lot of them thought it was a position that would come with a lot of incentives, but over time, their view started changing, and now they have a clear knowledge of their roles and responsibilities and the impact their work would make in their community.

"The workshop has really changed my perspective and mind toward WDC roles and responsibilities. I thought that the position comes with some form of money or incentives attached to it like I will now be paid a monthly allowance for working as a WDC, and this training is to prepare me for the kind of work I am to do, but now all that has changes as I have a better understanding of how WDCs are to operate with the PHC staff, and our responsibilities towards ensuring that problems at the facilities are resolved quickly for the benefit of our people especially the women and children. Now, and if possible, the WDC meeting with facility staff will now be conducted weekly or at least fortnightly" OM.

Participants were very enthusiastic about the relevance of the training and its benefits to their work. They agreed that the workshop exceeded their expectations as the content of the training was quite technical, but facilitation of the content was very simple with engaging exercises and participatory processes, which enabled them to learn easily. As stated by the WDC from Ipetu Ijesha ward, Oriade LGA,

"The training was very good for someone like me who doesn't understand so much English, the facilitators used local language sometimes they engaged some of us the participants to translate exactly what was taught in summary and it helped people like me, also I was sitting close to my OIC at the workshop so if I did not understand certain things, she explained to me. The drama on the roles and responsibilities of the WDC during the workshop was very useful. It made me to understand exactly what I'm to do and how to ensure that everybody, especially our women access the services and how to mobilize the community to support the facility" SM.

\section{Improved Quality of Service at the PHCs Following BHCPF Training}

Most of the participants agreed that a lot has changed very quickly in their wards and supported PHCs facilities since the end of the training. Some of the WDC has facilitated the reconnection of electricity in their facilities to the national power grid after several years without electricity, boreholes have started functioning, some of the WDCs have held town hall meetings in their community to raise awareness about the new BHCPF program, services available at the facilities and it benefits to every member of the community. Some of the WDCs have mobilized resources such as hospital furniture and equipment for their facilities, and all have held regular meetings with their facilities staff to review their scorecards, identify gaps, develop quality improvement plans and business plans to address the identified gaps, and have submitted same to the State PHCDB for necessary technical and financial support to address these issues. All of these have contributed immensely to the improved quality of services provided at the PHC facilities in their various wards. As stated by the Alekuwodo Ward WDC chair,

"Immediately after our training at IjebuIjesha, I met with the other WDCs to give them feedback on the training and the enormous tasks ahead of us, and then we also met with the PHC staff to look at the scorecards and identify immediate gaps we can address. One of the gaps was that the facility has been cut off from electricity supply for the past 4 years ago and because of this our staff cannot work late into the night, and the borehole is not working because no electricity our staff have to fetch water from neighbors house every day to use in the facility. Fortunately, the Electricity distribution agency 
(NEPA) official is also part of the committee, and his house is just down the street, so we complained to him about the situation, and he sent his boys from the NEPA office the following day to access the situation. By the very next day, they were here with their ladder to fix the problem, and now we have electricity in the facility our borehole is bringing water now even community members are coming to the facility to fetch water" OWC.

"I and my ward, we met with the facility staff and the major gap is the lack of bed and mattress for the PHC, we met our people and explained that pregnant women are not using the facility because of lack of bed and some other equipment. To my surprise, people started donating some gave us 500-naira others less and now we have 2 beds, mattress, and other furniture like tables, plastic chairs, and benches for our facility - WDC Ayegbogbo".

\section{Engagement with Community Level Stakeholders in Health:}

All the WDCs described the relationship between them and the PHC staff as very cordial and strong. The relationship was further strengthened after the training, which clarified the roles and responsibilities of the various stakeholders in health, especially the health facility staffs and the WDCs. They hold regular meetings, review quality improvement plans together, discuss strategies to address quality issues, work closely to ensure that all members of the community are benefiting from the program, and there is transparency in all that is done.

The Local government health authority supervises the work of the facilities staff and also provides support by participating in some of the meetings with the WDCs to discuss progress and challenges. This is especially important in the implementation of the BHCPF program, where WDCs are co-signatories to the official account of the facilities. As a result of this close collaboration between WDCs and PHC facilities staff, the quality of services rendered in the facilities has improved in facilities, staff are showing more commitment to their work to due improved conditions at the health facilities and the increase in client load to their facility has kept them busy, motivating them and giving them a sense of responsibility. As stated by the WDC from Oke Baale.

"The facility staff and we, the WDCs in my ward, work cordially together, we understand what needs to be done, and we are ensuring that we do the little we can as politicians to support our people. In my own ward, the chairman recently brought and donated essential medicines to all the facilities in the wards as a result of our visit to him. In fact, the focal centre got double the share of the drugs because of the clients that are now trooping in. Politicians don't joke with this type of thing as it projects them in a good light, and they use it to score political marks for next campaign, so we are using every means to get them to work four people now".

"Pregnant women and nursing mothers are now patronizing our PHC facility in the ward. In fact, the day before yesterday, my family benefitted from the free services because my pregnant wife delivered a bouncing baby boy safely at the ipetu ijesha PHC without us paying anything. We thank God, and we want the government to continue doing what they are doing now". Last week the OIC complained to me that work is too much now as women prefer to come to our centre they travel from very far to our place and it is because of the free services especially the drugs, the program is very good".

\section{Discussions}

The study sought to determine the extent to which capacity building/training of Ward development committees in BHCPF supported PHCs has contributed to the provision of quality services in the BHCPF supported facilities. The focus group discussion provided answers to the following research questions how did the capacity building of WDCs on BHCPF inform their roles in $\mathrm{PHC}$ management and inspire their 
involvement? How did the capacity building/training of the Ward development committee's members awaken their understanding of a relationship between the roles of WDCs and the quality of services at the PHCs?

The establishment of Ward Development Committees was facilitated by the state primary health care development agency as stipulated or recommended in national guidelines, and there are still gaps in the composition of the WDCs in the LGAs. Women's poor representation in the WDCs have an implication on the health outcomes, and indices in Osun state as women voices will not be heard, and quality improvement of health services may not take issues that affect women into consideration. This finding is consistent with other studies by Iyanda and Akinyemi, which found that in some wards, it was observed that female participation was very minimal [12]. The study also agrees with the findings of the Nigeria Health Watch that female leadership in the health sector is not only important to make a case for inclusiveness, gender equity, and representation in global health leadership, but a lack of this representation can also be said to have implications for the health outcomes and indices in Nigeria [13].

\section{Role of WDC in Health Management}

Prior to the BHCPF training, the WDCs in Osun state lacked understanding of their defined roles and responsibilities in the management of $\mathrm{PHC}$ as specified in the national guidelines and therefore could not perform most of their task/functions effectively. Creating awareness about the availability of services in the PHCs was not a priority for the WDCs. This resulted to low patronage and low utilization of services by the community members and women. This is consistent with findings by [14], Azuh, Agofure, and Sarki that the factors that affected the functionality of the WDCs include poor understanding of their functions by both the WDC and the community members, lack of incentives, the lopsided composition of the WDCs, absence of quality service in the health facilities (lack of skilled manpower, equipment, and drugs), lack of 24 hours service in most facilities, poor understanding by the health facility staff of the roles of the WDC in PHC programmes and their hostile attitude towards the WDC members $[14,15,16]$.

\section{Capacity Building on BHCPF for WDCs}

The commencement of the BHCPF program in Osun state-provided opportunity for the capacity building training of WDCs and Health workers on their roles and responsibilities in ensuring that success of the program in the state. The use of adult learning principles and teaching methods during the entire training promoted the learning of WDCs and health care workers. Misconceptions and non-clarity on roles, responsibilities of stakeholders in any program, and relationship lines expectations between the WDCs and health facility staff leads to mistrust, disharmony, unrealistic expectations, and nonachievement of the goals /objectives of the program.

This may lead to a hostile attitude of the WDCs to the health workers and vice versa and may disrupt the provision of quality health services to the clients in the community, resulting in poor maternal and child health indices in the community. This is consistent with the findings by $[17,18]$, that CDC/CDA members who took the lead in implementing health and developmental interventions had inadequate knowledge of the WHS, reflected the past, when community involvement in PHC implementation had been a kind of tokenism. Lessons from the past had not been effectively utilized, and the direct and/or indirect impacts of this neglect are probably responsible even for the country's current poor health development and unacceptable vital statistics (Infant, Under-five, and Maternal Mortality Rates). When communities have adequate knowledge and are fully mobilized, they participate actively in the running of their PHC services. Service 
utilization and coverage improve, and the indices for measuring the quality of health are better $[17,18]$.

\section{Improved Quality of Service at the PHCs following BHCPF Training}

Our finding revealed that there was a significant improvement of services rendered by WDCs following the BHCPF training. When stakeholders in PHC management are well informed about their roles and responsibilities and are motivated by capacity-building efforts such as training and mentoring, there is an increased likelihood of improved functionality of the stakeholders (WDCs) in response to the needs of the health facilities. WDCs are more likely to perform their specified roles and responsibilities once they have a clear understanding about them and are more likely to be effective in addressing identified needs of the facilities by mobilizing local resources to address them.

This agrees with the study findings [19] that health committees provide a mechanism that enables communities to be active and informed participants in the creation of a responsive health system that serves them efficiently and the results from the survey of PHC facilities by [20] also showed that community health committees were the major source of support for building maintenance in majority of the selected PHC facilities.

\section{Conclusion}

Findings from this qualitative research provide evidence that in communities where the BHCPF program commenced and is implemented according to the national guidelines with requisite training for the ward development committees, there is increased participation and commitment by the WDCs to ensure that PHCs are supported to provide quality services to the communities they serve. This is evident in the way trained WDCs mobilized community resources to support the PHCs; the improved relationship between the
WDCs and health workers which led to an improved understanding of the roles and responsibilities of the stakeholders in PHC management in the wards. The BHCPF program will guarantee improved access to quality health care to vulnerable groups, especially women of childbearing age and children. States and communities where the BHCPF scheme are being implemented stand a better chance of providing quality health care services to pregnant women, children, and vulnerable groups in the community, making equitable and accessible health care service and delivery possible in these communities. The communities also own the program as they see themselves as major stakeholders in the scheme ensuring the sustainability of the scheme in the communities where it is implemented.

\section{Recommendations}

There is a need for states governments in Nigeria to adopt the BHCPF program, a veritable scheme that will contribute tothe provision of equitable health care services to all Nigerians andultimately contribute to the achievement ofo universal health coverage to all Nigerians in the nearest future. The training and capacity development provided to health care workers and WDCs participating in the scheme are very beneficial.

It provides a road map for the provision of quality health care services to the most vulnerable in society. The BHCPF training provided an opportunity for PHCs staff and WDCs to jointly identify quality issues or gaps in their facilities, analyze data from their facilities to identify problems in terms of why community members were not accessing health care, work closely with the WDCs and their supervisors at the local government health council to implement strategies that will improve access to services for the population at the PHC. All these efforts are geared towards ensuring that quality health care services are provided to all Nigerians, especially the most vulnerable in the community. 


\section{Acknowledgement}

The authors express gratitude to members of the ward development committees and Primary Health Care (PHC) workers in Osun state for consenting to participate in the study. We acknowledge the support of all who in one way or the other has contributed to this study, especially Mrs. Janet Adedeji, Officer in Charge of Isale agbara $\mathrm{PHC}$ in organizing the discussion sessions and mobilization of resources and data gathering during the covid 19 lockdown in the

\section{References}

[1] National Population Commission (NPC) [Nigeria] and ICF. 2019. Nigeria Demographic and Health Survey 2018. Abuja, Nigeria, and Rockville, Maryland, USA: NPC and ICF.

[2] World Bank, 2017. https://data.worldbank.org/indicator/SH.DYN.MOR T?locations=NG.

[3] World Bank Group 2018: Country focus: Nigeria Biannual Economic Update Investing in Human Capital for Nigeria's Future http://documents.worldbank.org/curated/en/3467715 42864299850/pdf/132316-21-11-2018-17-31-9NigeriaBEUAMF.pdf.

[4] National Bureau of Statistics (NBS) and United Nations Children's Fund (UNICEF), 2017: Multiple Indicator Cluster Survey 2016-17, Survey Findings Report. Abuja, Nigeria: National Bureau of Statistics and United Nations Children's Fund.

[5] Nigeria Health Watch 2018, Official Gazette of the National Health Act- FGN 2014: https://nigeriahealthwatch.com/wpcontent/uploads/bsk-pdf-manager/2018/07/01_Official-Gazette-of-the-National-Health-ActFGN.pdf retrieved 12.09.2020.

[6] Federal Ministry of Health, 2020: Guideline for the Administration, Disbursement, and Monitoring of the Basic Health Care Provision Fund (BHCPF) retrieved

https://www.health.gov.ng/doc/BHCPF-2020-

Guidelines.pdf. state, including all staff of the State Ministry of Health DPRS unit.

\section{Conflict-of-interest Statement}

The authors received no funding for this study and have no conflicts of interest to declare. All co-authors have seen and agree with the contents of the manuscript, and there is no financial interest to report. We certify that the submission is original work and is not under review at any other publication.

[7] Awal, A., Ezenwa S., Atobatele S., Nzobiwu A., \& Uweiza H., 2020. Preliminary learnings from Nigeria's Basic Health Care Provision Fund, https://r4d.org/blog/preliminary-learnings-fromnigerias-basic-health-care-provision-fund/.

[8] Oginni A. S., 2019. Update on Basic Health Care Provision Fund (BHCPF) Implementation in Osun State: Report submitted to BHCPF State Steering Committee (Unpublished).

[9] Oyebode O., 2019. Update on Basic Health Care Provision Fund (BHCPF) Implementation in Osun State: Progress and Challenges. Report submitted to BHCPF State Steering Committee (Unpublished).

[10]National Primary Health Care Development Agency (NPHCDA) (2018): Ward Health System, 2nd Ed. August 2018.

[11]National Primary Health Care Development Agency, 2014. Minimum Standards for Primary Health Care in Nigeria 2014.

[12] Iyanda, O. F., \& Akinyemi, O. O., 2017. Our chairman is very efficient: community participation in delivering primary health care in Ibadan, Southwest Nigeria. The Pan African Medical Journal, $27, \quad 258$. https://doi.org/10.11604/pamj.2017.27.258.12892 https://www.ncbi.nlm.nih.gov/pmc/articles/PMC566 0304/ 235.2021.

[13] Nigeria Health Watch (2020): The need for women's leadership in global health - The Nigeria experience; https://nigeriahealthwatch.com/the-needfor-womens-leadership-in-global-health-the-nigeriaexperience/ retrieved 21.5.21. 
[14] Oyari F.O., Ogbonnaya L.U., Ota M.O., \& Azuogu B., 2017: How Ready are the Ward Development Committees to Facilitate Universal Health Coverage in Ebonyi State, Nigeria; Journal of Primary Health Care and General Practice 1 (1) 005 www.scientonline.org https://scientonline.org/openaccess/how-ready-are-the-ward-developmentcommittees-to-facilitate-universal-health-coveragein-ebonyi-state-nigeria.pdf retrieved 21.05.2021.

[15] Azuh D. E., 2017; The Role and Challenges of Ward Development Committees in Promoting Grassroots Health Awareness in Ogun State Nigeria; Journal of Business and Management 19 (7) 41-48 www.iosrjournals.org.

[16] Agofure, O., \& Sarki, E., 2017. Utilization of Primary Health Care Services in Jaba Local Government Area of Kaduna State Nigeria. Ethiopian Journal of health sciences, 27 (4), 339-350. https://doi.org/10.4314/ejhs.v27i4.5.

[17] Srivastava, A., Gope, R., Nair, N. et al. 2015, Are village health sanitation and nutrition committees fulfilling their roles for decentralised health planning and action? A mixed-methods study from rural eastern India. BMC Public Health 16, 59 https://doi.org/10.1186/s12889-016-2699-4.

[18] Abosede O.A, Campbell P.C., Olufunlayo T., Sholeye O.O., 2012 Establishing a Sustainable Ward Health System in Nigeria: Are Key Implementers Well Informed? J Community Med Health Educ 2:164. DOI: 10.4172/2161-0711.1000164.

[19] Mulumba, M., London, L., Nantaba, J., \& Ngwena, C. 2018. Using Health Committees to Promote Community Participation as a Social Determinant of the Right to Health: Lessons from Uganda and South Africa. Health and human rights, 20(2), 11-17.

[20]Gupta M.D, Gauri V., Khemani S., 2003, Decentralized Delivery of Primary Health Services in Nigeria. Africa Region Human Development Working Paper Series. Washington, DC: The World Bank; 2003. 